\title{
HYDROTHERMAL REACTIONS \\ FOR MATERIALS SCIENCE AND ENGINEERING
}

An Overview of Research in Japan 


\title{
HYDROTHERMAL REACTIONS FOR MATERIALS SCIENCE AND ENGINEERING
}

\section{An Overview of Research in Japan}

\author{
Edited by \\ Shigeyuki Sōmiya \\ The Nishi-Tokyo University, Japan
}

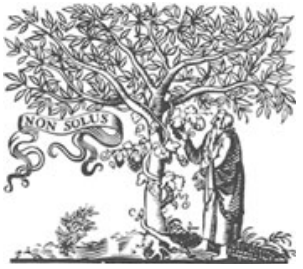

ELSEVIER APPLIED SCIENCE LONDON and NEW YORK 


\section{ELSEVIER SCIENCE PUBLISHERS LTD}

Crown House, Linton Road, Barking, Essex IG11 8JU, England

Sole Distributor in the USA and Canada

ELSEVIER SCIENCE PUBLISHING CO., INC.

655 Avenue of the Americas, New York, NY 10010, USA

WITH 64 TABLES AND 505 ILLUSTRATIONS

Selection and editorial matter (C) 1989 ELSEVIER SCIENCE PUBLISHERS LTD

Softcover reprint of the hardcover 1st edition 1989

British Library Cataloguing in Publication Data

Hydrothermal reactions for materials science and engineering.

1. Powder metallurgy

I. Sōmiya, Shigeyuki

$671.3 \% 7$

ISBN-13: 978-94-010-6819-2

e-ISBN-13: 978-94-009-0743-0

DOI: $10.1007 / 978-94-009-0743-0$

\section{Library of Congress Cataloging-in-Publication Data}

Hydrothermal reactions for materials science and engineering: an overview of research in Japan / edited by Shigeyuki Sōmiya.

p. cm.

Bibliography: $p$

Includes index.

1. Powder metallurgy. I. Sōmiya, Shigeyuki.

TN695.H93 1989

$671.3 \cdot 7-\mathrm{dc} 20$

$89-35565$

No responsibility is assumed by the Publisher for any injury and/or damage to persons or property as a matter of products liability, negligence or otherwise, or from any use or operation of any methods, products, instructions or ideas contained in the material herein.

\section{Special regulations for readers in the USA}

This publication has been registered with the Copyright Clearance Center Inc. (CCC), Salem, Massachusetts. Information can be obtained from the CCC about conditions under which photocopies of parts of this publication may be made in the USA. All other copyright questions, including photocopying outside the USA, should be referred to the publisher.

All rights reserved. No part of this publication may be reproduced, stored in a retrieval system, or transmitted in any form or by any means, electronic, mechanical, photocopying, recording, or otherwise, without the prior written permission of the publisher. 
To Professor Emeritus E. F. Osborn, The Pennsylvania State University, University Park, Pennsylvania, USA

Without the benefit of study at the Department of Geochemistry, College of Mineral Industries,

The Pennsylvania State University, under a Fulbright Travel Grant,

I would not have been able to commence my studies on hydrothermal reactions 


\section{Preface}

According to the late Professor Emeritus Seitaro Tsuboi, ${ }^{1}$ the word 'hydrothermal' was used as early as 1849 by a British geologist, Sir Roderick Murchison (1792-1871), in relation to the action of heated water in bringing about change in the earth's crust. The term abounds in later geological literature, and is most frequently met in connection with the processes that take place at a stage near the closing in the course of consolidation of magma. When a cooling magma reaches that stage, the residual liquid contains a large proportion of volatile components, chiefly water, and further cooling results in the formation of minerals of special interest or ore-deposits.

A great concern of Tsuboi's as a petrologist was to elucidate the details of the nature of various actions involved in these 'hydrothermal processes', of which little was known. It is remarkable that, in the last few decades, extensive high-temperature and high-pressure experiments, in which water plays an important role, have become practicable in laboratories, owing to the development of new apparatus and new methods. As a result, the knowledge essential to the elucidation of 'hydrothermal processes' has been improved, but is still far from complete.

On the other hand, we are informed that, apart from the geological interest, research workers in the synthesis of engineering materials are greatly concerned with 'hydrothermal reactions', and that their studies along this line are being carried on efficiently. Armed with this information, Tsuboi considered it highly desirable to provide arrangements for a sort of interdisciplinary conference to discuss subjects of common interest, which would be of benefit to both earth scientists and materials engineers. Over the years, the idea of such a joint meeting occurred repeatedly to him.

In the field of materials science and engineering, ordinary use of the term "hydrothermal synthesis' usually refers to heterogeneous reactions in aqueous media above $100^{\circ} \mathrm{C}$ and 1 bar. $^{2}$

'Hydrothermal crystal growth' is

a process in which an aqueous solution is held at high temperature and pressure in order to dissolve a material (the nutrient) in one part of the system, transport it to another part of the system and there deposit it, either on a seed, or on small crystals attached to the containing vessel by epitaxy. This process is usually carried out in sealed vertical autoclaves with a temperature difference $(\Delta T)$ established between the top and bottom of the vessel. Usually the nutrient is placed in the lower, hotter part of the autociave and the seeds are mounted in the cooler upper part. The seeds are single crystal plates properly oriented and mounted on a suitable wire frame.

Transport of the hot solution from the region containing the nutrient to the region containing the seeds is by convection. Once the solution reaches the growth region it becomes supersaturated with respect to the seed material and deposits on the seeds. The cooler depleted solution then returns to the hotter zone by convection and dissolves more nutrient. ${ }^{3}$

There are many types of hydrothermal reaction:

1. Hydrothermal treatment.

2. Hydrothermal metamorphism (hydrothermal alternation).

3. Hydrothermal growth.

4. Hydrothermal synthesis (hydrothermal reactions).

5. Hydrothermal dehydration.

6. Hydrothermal decomposition. 
7. Hydrothermal extraction.

8. Hydrothermal sintering.

9. Hydrothermal reaction sintering.

10. Hydrothermal hot isostatic processing.

11. Hydrothermal crystallization.

12. Hydrothermal deposition for thin films.

13. Hydrothermal corrosion.

14. Hydrothermal etching.

15. Testing under hydrothermal conditions.

After 1950, Professors E. F. Osborn, O. F. Tuttle and Rustum Roy of the Pennsylvania State University used hydrothermal experiments for mineral synthesis and for phase equilibrium studies. Preparation of homogeneous starting materials is very important in phase equilibrium studies, which is one of the reasons why hydrothermal conditions are used for their preparation.

In Japan, hydrothermal work first appeared in 1926, by Dr Tominosuke Katsurai. His report, entitled 'Soda treatment of the aluminum ore', dealt with hydrothermal extraction. On hydrothermal synthesis, Professor Shoichiro Nagai reported on calcium silicate in 1931. The Morey bomb used after the Second World War was reported by Professor Raisaku Kiyoura in 1952 for hydrothermal alternation and hydrothermal synthesis.

After the mid-1970s there were several reports related to hydrothermal reactions, since such reactions can be considered for use in ceramic processing, such as for powder preparation, reaction sintering, etc. Powder prepared by hydrothermal preparation is not agglomerated, is fine-grained, has a narrow grain size distribution and consists of single crystals. Such processing therefore received wide attention. Many papers have been published in Japan and several companies produce powders such as $\mathrm{ZrO}_{2}$ under hydrothermal conditions. Reports relating to hydrothermal reactions in such fields as powder preparation, sintering, corrosion, crystal growth, etc., also appeared.

Following the First International Symposium on Hydrothermal Reactions in March 1982, it was decided to maintain communications between workers in different fields, and on 25 September 1982 the Hydrothermal Reactions Study Group was established. Since then papers related to hydrothermal reactions have increased, both in Japanese and in English.

This book is a compilation of English language reports by Japanese workers on hydrothermal reactions related to materials science and engineering. The book shows the development and the present status of R \& D in Japan. The papers are scattered in many journals, which is one reason for collecting them together. I am convinced that this book will promote the R \& D of hydrothermal reactions.

Shigeyuki Sōmiya

\section{References}

1. S. Tsuboi, in S. Sōmiya (ed.), Proceedings of the First International Symposium on Hydrothermal Reactions, 22-26 March 1982 (Gakujutsu Bunken Fukyu-kai, 1983).

2. A. Rabenau, Angew. Chem. Int. Ed. Engl., 24 (1985) 1026-1040.

3. R. A. Laudise, Solid State Phys., 12 (1961) 150. 


\section{Acknowledgements}

I wish to express my gratitude to the following authors for agreeing to the reproduction of their papers:
Dr Shin-ichi Hirano
Dr M. G. M. U. Ismail
Dr Kiyoshi Matsuoka
Dr Taiko Mitsusio
Dr Kazuo Nakamura
Dr Sadao Taki
Dr Eiji Tani
Dr Hideo Toraya
Dr Nakamichi Yamasaki
Dr Kazumichi Yanagisawa
Dr Masahiro Yoshimura

I would also like to thank the following publishers for granting permission to reproduce copyright material:

Academic Press, Inc.

American Ceramic Society

American Chemical Society

Atomic Energy Society of Japan

Center for Academic Publications, Japan

Ceramic Society of Japan

Chapman \& Hall Ltd

Chemical Society of Japan

Elsevier Science Publishers BV

Elsevier Science Publishing Co., Inc.

Japanese Association of

Mineralogists, Petrologists and

Economic Geologists

\author{
Kodansha, Japan \\ Materials Research Society \\ Nagaoka Technical College \\ National Bureau of Standards \\ Pergamon Press Ltd \\ Plenum Press \\ Research Laboratory of \\ Engineering Materials, Tokyo \\ Institute of Technology \\ Verlag J. A. Barth, Leipzig \\ Verlag Schmid GmbH, Freiburg
}

and also the organizers of the following conferences:

Expermat 87 (Bordeaux)

8th AIRAPT Conference/19th EHPRG Conference (1981, Sweden)

4th International Conference on Crystal Growth (1974, Tokyo)

4th International Conference on High Pressure (1974, Kyoto)

2nd International Symposium on Ceramic Materials and Components for Engines (1986, Germany)

International Symposium on Factors in Densification and Sintering of Oxide and Nonoxide Ceramics (1978, Japan)

1st International Symposium on Hydrothermal Reactions (1982, Japan)

Powder Metallurgy Conference (1986, Germany) 


\section{Contents}

Preface . . . . . . . . . . . . . . . . . . . . . . . . . . . .

Acknowledgements . . . . . . . . . . . . . . . . . $\mathrm{ix}$

\section{Part 1: Hydrothermal Reaction Sintering}

Hydrothermal Reaction Sintering of $\mathrm{Pure}_{\mathrm{Cr}_{2} \mathrm{O}_{3}}$. . . . . . . . . 3 Shin-ichi Hirano and Shigeyuki Sōmiya

Hydrothermal Reaction Sintering of $\mathrm{Cr}_{2} \mathrm{O}_{3}$ and Iron Oxides . . . . 4 Shigeyuki Sōmiya, Shin-ichi Hirano, Masahiro Yoshimura, Shuichi Itoh and Hideyuki Kanai

Fabrication of Dense, Nonstabilized $\mathrm{ZrO}_{2}$ Ceramics by Hydrothermal Reaction Sintering Masahiro Yoshimura and Shigeyuki Sōmiya

Hydrothermal Reaction Sintering of Monoclinic Zirconia . . . . . 16 Masahiro Yoshimura and Shigeyuki Sōmiya

Hydrothermal Reaction-Sintering of Monoclinic $\mathrm{HfO}_{2}$. . . . . . . . 24

Hideo Toraýa, Masahiro Yoshimura and Shigeyuki Sōmiya

Hydrothermal Reaction Sintering of High Density Sintered Oxides . . . 26

Shigeyuki Sōmiya

Hydrothermal Reaction Sintering of Oxides . . . . . . . . . . 37

Shigeyuki Sōmiya

Hydrothermal Preparation and Sintering of Fine Ceramic Powders . . . 46

Shigeyuki Sōmiya

The Processing of a Permalloy-Magnetite Composite by Hydrothermal Reaction Sintering

Masahiro Yoshimura, Shigeyuki Sōmiya, Kimiyuki Kamino and

Takahiro Nakagawa

\section{Part 2: Hydrothermal Oxidation}

Preparation of Zirconia Fine Powders by the Reactions Between Zirconium Metal and High Temperature-High Pressure Solutions.

Masahiro Yoshimura, Shinya Kikugawa and Shigeyuki Sömiya

Preparation of Fine Monoclinic Hafnia Powders by Hydrothermal Oxidation

Hideo Toraya, Masahiro Yoshimura and Shigeyuki Sōmiya 
Synthesis and Sintering of Zirconia Fine Powders by Hydrothermal Reactions from Zirconium Metal and High-Temperature High-Pressure Solutions Masahiro Yoshimura and Shigeyuki Sōmiya

Hydrothermal Oxidation of Hf Metal Chips in the Preparation of Monoclinic $\mathrm{HfO}_{2}$ Powders Hideo Toraya, Masahiro Yoshimura and Shigeyuki Sömiya

Reaction Kinetics in the Hydrothermal Oxidation of $\mathrm{Hf}$ Hideo Toraya, Masahiro Yoshimura and Shigeyuki Sōmiya

Preparation of Mixed Fine $\mathrm{Al}_{2} \mathrm{O}_{3}-\mathrm{HfO}_{2}$ Powders by Hydrothermal Oxidation . Hideo Toraya, Masahiro Yoshimura and Shigeyuki Sōmiya

Preparation of Zirconia-Alumina Fine Powders by Hydrothermal Oxidation of $\mathrm{Zr}-\mathrm{Al}$ Alloys . Shigeyuki Sōmiya, Masahiro Yoshimura and Shinya Kikugawa

Formation of $\mathrm{TiO}_{2}$ and $\mathrm{ZnO}$ Powders by Hydrothermal Oxidation of $\mathrm{Ti}$ and $\mathrm{Zn}$ Metals Masahiro Yoshimura, Hiroyuki Ohira and Shigeyuki Sōmiya

\section{Part 3: Hydrothermal Growth}

Crystal Growth of Magnetite under Hydrothermal Condition with Hydrogen S. Hirano and S. Sōmiya

Hydrothermal Growth of Brucite Crystals . . . . Kazuo Nakamura, Shin-ichi Hirano and Shigeyuki Sōmiya

Hydrothermal Crystal Growth of Magnetite in the Presence of Hydrogen Shin-ichi Hirano and Shigeyuki Sömiya

Crystal Growth of Sodium Iron Titanium Bronze Compounds under Hydrothermal Conditions Shin-ichi Hirano, M. G. M. U. Ismail and Shigeyuki Sōmiya

Hydrothermal Growth of $\mathrm{Y}_{2} \mathrm{O}_{3}$-Stabilized Cubic $\mathrm{ZrO}_{2}$ Crystals Kazuo Nakamura, Shin-ichi Hirano and Shigeyuki Sōmiya

Hydrothermal Growth of Fayalite Crystals Shigeyuki Sōmiya, Shin-ichi Hirano and Yutaka Iwai

Hydrothermal Growth of Fayalite Crystals

S. Hirano, Y. Iwai, S. Sōmiya and S. Saito

Hydrothermal Growth of Quartz Crystals in $\mathrm{NaCl}$ Solution Masahiro Hosaka and Sadao Taki

Hydrothermal Crystal Growth of Perovskite-Type Fluorides Shigeyuki Sömiya, Shin-ichi Hirano, Masahiro Yoshimura and Kazumichi Yanagisawa

Hydrothermal Growth of Quartz Crystals in $\mathrm{KCl}$ Solution Masahiro Hosaka and Sadao Taki

Hydrothermal Crystal Growth of Mixed Crystals in the $\mathrm{KMnF}_{3}-\mathrm{KCoF}_{3}$ System Kazumichi Yanagisawa, Masahiro Yoshimura and Shigeyuki Sōmiya 
Hydrothermal Growth of Amethyst and Citrine in $\mathrm{NaCl}$ and $\mathrm{KCl}$ Solutions Masahiro Hosaka and Sadao Taki

Hydrothermal Growth of $\mathrm{La}^{3+}$-doped $\mathrm{SrF}_{2}$ Single Crystal . M. Yoshimura, K. J. Kim and S. Sömiya

Crystal Growth of Yttria Stabilized Zirconia (YSZ) under Hydrothermal Conditions Masahiro Yoshimura, Takehiro Hiuga and Shigeyuki Sōmiya

Hydrothermal Crystal Growth of Calcite in $\mathrm{NaCl}$ and $\mathrm{KCl}$ Solutions . Shin-ichi Hirano and Kö-ichi Kikuta

Hydrothermal Crystal Growth of $\mathrm{BaPb}_{1-x} \mathrm{Bi}_{x} \mathrm{O}_{3}(0 \leq x \leq 0 \cdot 30)$ Shin-ichi Hirano and Seiji Takahashi

Solubility and Hydrothermal Growth of Calcite Single Crystal in Nitrate Solutions Shin-ichi Hirano and Kō-ichi Kikuta

\section{Part 4: Crystallization}

Hydrothermal Preparation of Ultrafine Monoclinic $\mathrm{ZrO}_{2}$ Powder

Eiji Tani, Masahiro Yoshimura and Shigeyuki Sōmiya

Crystallization and Transformation of Zirconia under Hydrothermal Conditions H. Nishizawa, N. Yamasaki, K. Matsuoka and H. Mitsushio

Crystallization and Crystal Growth of $\mathrm{CeO}_{2}$ under Hydrothermal Conditions E. Tani, M. Yoshimura and S. Sōmiya

Formation of Ultrafine Tetragonal $\mathrm{ZrO}_{2}$ Powder under Hydrothermal Conditions Eiji Tani, Masahiro Yoshimura and Shigeyuki Sōmiya

Hydrothermal Crystallization and Crystal Growth of Un-doped and $\mathrm{ZrO}_{2}$-doped $\mathrm{CeO}_{2}$

Eiji Tani, Masahiro Yoshimura and Shigeyuki Sōmiya

Fine Zirconia Powders by Hydrothermal Processing Masahiro Yoshimura and Shigeyuki Sōmiya

Cubic Eu-doped Hafnia Ultrafine Particles Crystallized under Hydrothermal Conditions

Shigeyuki Sōmiya, Masahiro Yoshimura, Hideo Toraya and Yasuhito Fushii

Hydrothermal Processing of Ultrafine Single-Crystal Zirconia and Hafnia Powders with Homogeneous Dopants . . . . . . . . . . . . . Shigeyuki Sōmiya, Masahiro Yoshimura, Zenjiro Nakai, Kazumitsu Hishinuma and Takao Kumaki

\section{Part 5: Hydrothermal Synthesis}

Fluid Inclusions in Hydrothermally Synthesized Brucite Crystals . . . . . 263 Kazuo Nakamura, Shin-ichi Hirano and Shigeyuki Sōmiya

Hydrothermal Synthesis of Topaz Crystals . . . . . . . . . . .

Shigeyuki Sōmiya, Shin-ichi Hirano, Masahiro Yoshimura and Hironori Shima 
Hydrothermal Synthesis and Sintering of $\mathrm{LaCrO}_{3}$

Masahiro Yoshimura, Shen-tai Song and Shigeyuki Sōmiya

Synthesis of $\mathrm{LaCrO}_{3}$ under Hydrothermal Conditions

Masahiro Yoshimura, Shen-tai Song and Shigeyuki Sōmiya

Effects of Starting Materials and Temperature on the Hydrothermal Synthesis of

Aluminum Orthophosphate Kiyoshi Hasegawa, Keiichi Minegishi and Shigeyuki Sōmiya

Hydrothermal Synthesis of Oxides of Manganese Single Crystals

J. A. K. Tareen, B. Basavalingu, T. R. N. Kutty, G. T. Bhandge, M. Yoshimura and S. Sōmiya

Hydrothermal Synthesis and Growth of $\mathrm{La}_{1-x} \mathrm{Sr}_{x} \mathrm{FeO}_{3}(0 \leq x \leq 0 \cdot 1)$ Crystals Masahiro Yoshimura, Kazuhito Yamasawa and Shigeyuki Sōmiya

Synthesis of Magnetite Using Ilmenite under Hydrothermal Conditions M. G. M. U. Ismail, M. Yoshimura and S. Sōmiya

Synthesis of Vanadium Sulfides under High Pressure . . . . . . Masao Yokoyama, Masahiro Yoshimura, Masataka Wakihara, Shigeyuki Sōmiya and Masao Taniguchi

Hydrothermal Synthesis of Gallium Orthophosphate Crystals Shin-ichi Hirano, Kazuo Miwa and Shigeharu Naka

Hydrothermal Synthesis and Properties of $\mathrm{BaPb}_{1-x} \mathrm{Bi}_{x} \mathrm{O}_{3}$ Shin-ichi Hirano and Seiji Takahashi

\section{Part 6: Hydrothermal Reactions}

Graphitization of Carbon in Presence of Calcium Compounds under Hydrothermal Condition by Use of High Gas Pressure Apparatus .
Shin-ichi Hirano, Kazuo Nakamura and Shigeyuki Sōmiya

Hydration of Calcium Aluminates (3:1, 12:7, 1:1, 1:2 and 1:6) in Phosphoric Acid Solutions at Various Temperatures

Kengo Yamazaki, Toshihiko Nakazawa, Masahiro Yoshimura and Shigeyuki Sōmiya

Immobilization of Radioactive Wastes in Hydrothermal Synthetic Rock: Lithification of Silica Powder Nakamichi Yamasaki, Kazumichi Yanagisawa, Satoshi Kanahara, Mamoru Nishioka, Kiyoshi Matsuoka and Jumei Yamazaki

Immobilization of Radioactive Wastes in Hydrothermal Synthetic Rock (II): Hydrothermal Synthesis of Pollucite

Kazumichi Yanagisawa, Satoshi Kanahara, Mamoru Nishioka and Nakamichi Yamasaki

Immobilization of Radioactive Wastes in Hydrothermal Synthetic Rock (III): Properties of Waste Form Containing Simulated High-Level Radioactive Waste . Kazumichi Yanagisawa, Mamoru Nishioka and Nakamichi Yamasaki

\section{Part 7: Hydrothermal Decomposition and Corrosion}

Decomposition of Ilmenite under Hydrothermal Condition (Preliminary Work) .

M. G. M. U. Ismail, Shin-ichi Hirano and Shigeyuki Sōmiya 
Decomposition of Ilmenite under Hydrothermal Condition M. G. M. U. Ismail and Shigeyuki Sōmiya

Reaction Products of $\mathrm{Si}_{3} \mathrm{~N}_{4}$ in Ammonia Solution at High Temperature under High Pressure Shigeyuki Sōmiya, Giichi Sudoh, Mitsuo Tanaka and Yasubumi Fukaya

Hydrothermal Decomposition of Polychlorinated Biphenyls Nakamichi Yamasaki, Takaji Yasui and Kiyoshi Matsuoka

Decomposition of Ilmenite in $\mathrm{KOH}-\mathrm{H}_{2} \mathrm{O}$ Solutions under High-Pressure Shin-ichi Hirano, M. G. M. U. Ismail and Shigeyuki Sōmiya

Oxidation of SiC Powder by High-Temperature, High-Pressure $\mathrm{H}_{2} \mathrm{O}$ Masahiro Yoshimura, Jun-ichiro Kase and Shigeyuki Sömiya

Dissolution and Reaction of Yttria-Stabilized Zirconia Single Crystals in Hydrothermal Solutions Masahiro Yoshimura, Takehiro Hiuga and Shigeyuki Sōmiya

Role of $\mathrm{H}_{2} \mathrm{O}$ on the Degradation Process of Y-TZ Masahiro Yoshimura, Tatsuo Noma, Katsuichi Kawabata and Shigeyuki Sōmiya

Oxidation of Non-oxide Ceramics by High-Temperature High-Pressure Water . Masahiro Yoshimura, Jun-ichrō Kase, Makoto Hayakawa and Shigeyuki Sōmiya

\section{Part 8: Hydrothermal Hot Pressing}

Solidification of Glass Powder by a Hydrothermal Hot-Pressing Technique Mamoru Nishioka, Kazumichi Yanagisawa and Nakamichi Yamasaki

A Hydrothermal Hot-Pressing Method: Apparatus and Application N. Yamasaki, K. Yanagisawa, M. Nishioka and S. Kanahara

Immobilization of Radioactive Wastes by Hydrothermal Hot Pressing Kazumichi Yanagisawa, Mamoru Nishioka and Nakamichi Yamasaki

\section{Part 9: Hydrothermal Hot Isostatic Pressing}

Fabrication of Phosphate-Bonded Mica Ceramics by Hot Isostatic Processing T. Hattori, A. Yahata, J. Mohri, M. Yoshimura and S. Sōmiya

Fabrication of Nonadditive Mica Ceramics by Hot Isostatic Processing Takeo Hattori, Atsushi Shigemori, Jun-ichi Mohri, Masahiro Yoshimura and Shigeyuki Sōmiya

Sintering of Synthetic Mica by a Hydrothermal Equipment .

T. Hattori, J. Mori, M. Yoshimura and S. Sōmiya

Sintering of Synthetic Mica by a Hydrothermal Hot Isostatic Process

Takeo Hattori, Jun-ichi Mohri, Masahiro Yoshimura and Shigeyuki Sōmiya

High-Pressure Hot Isostatic Pressing of Synthetic Mica

Takeo Hattori, Masahiro Yoshimura and Shigeyuki Sōmiya 


\section{Part 10: Nitridation}

Reactions of Titanium Metal Powders with High-Temperature High-Pressure Ammonia S. Sōmiya, M. Yoshimura and H. Toraya

Oxidation of $\mathrm{Si}_{3} \mathrm{~N}_{4}$ and $\mathrm{SiC}$ by High Temperature-High Pressure Water Vapour M. Yoshimura, J. Kase and S. Sōmiya

Nitridation of Titanium and Zirconium Powders Mixed with Ammonium Chloride under High Temperature-High Pressure Ammonia

Shigeyuki Sōmiya, Kazuo Suzuki and Masahiro Yoshimura

Nitridation of Titanium and Zirconium Powders Mixed with Ammonium Chloride under High Temperature-High Pressure Ammonia

Shigeyuki Sōmiya, Kazuo Suzuki and Masahiro Yoshimura

\section{Part 11: Phase Diagrams}

Phase Equilibria in the System $\mathrm{MgO}-\mathrm{RCl}(\mathrm{R}=\mathrm{Li}, \mathrm{Na}$ and $\mathrm{K})$ : Solution under Hydrothermal Conditions by Means of a Capsule Bursting Method Shigeyuki Sōmiya, Kazuo Nakamura, Shin-ichi Hirano and Shinroku Saito

Phase Equilibria in the System $\mathrm{Nd}_{2} \mathrm{O}_{3}-\mathrm{P}_{2} \mathrm{O}_{5}-\mathrm{H}_{2} \mathrm{O}$ at $500^{\circ} \mathrm{C}$ under $100 \mathrm{MPa}$ and Synthesis of $\mathrm{NdP}_{5} \mathrm{O}_{14}$ Crystals

Masahiro Yoshimura, Kazutaka Fujii and Shigeyuki Sōmiya

The Confirmation of Phase Equilibria in the System $\mathrm{ZrO}_{2}-\mathrm{CeO}_{2}$ below $1400^{\circ} \mathrm{C}$ Masahiro Yoshimura, Eiji Tani and Shigeyuki Sōmiya

Revised Phase Diagram of the System $\mathrm{ZrO}_{2}-\mathrm{CeO}_{2}$ below $1400^{\circ} \mathrm{C}$

Eiji Tani, Masahiro Yoshimura and Shigeyuki Sōmiya

Index 